\title{
Identifikasi Telur Cacing Nematoda Usus Pada Siswa SDN Cimerang Kabupaten Bandung Barat
}

\author{
*Dwi Davidson Rihibiha ${ }^{1)}$, Ria Nurul Aqmalia ${ }^{1)}$ \\ ${ }^{1}$ Program Studi TLM, Sekolah Tinggi Ilmu Kesehatan Jenderal Achmad Yani Cimahi \\ *Correspodence author: Dwi Davidson Rihibiha, dwirihibiha@gmail.com, Bandung, Indonesia
}

\begin{abstract}
Abstrak
Infeksi kecacingan sampai saat ini masih menjadi masalah kesehatan di indonesia. Soil-transmitted helminths (STHs) merupakan salah satu golongan cacing yang menyebabkan kecacingan. Sekolah Dasar merupakan salah satu tempat palig beresiko terpapar cacing nematoda usus STH. Penelitian menunjukkan prevalensi kasus kecacingan yang tinggi di beberapa Sekolah Dasar di Kabupaten Bandung Barat. Sekolah Dasar yang akan dijadikan objek pada penelitian ini adalah SDN Cimerang, Bandung Barat, yang juga berada di wilayah pemukiman padat. Tujuan dari penelitian ini adalah mengetahui adanya telur cacing nematoda usus pada siswa SDN Cimerang Kecamatan Cipatat Kabupaten Bandung Barat. Sampel yang digunakan berasal dari feses siswa sebanyak 10 orang. Penelitian ini menggunakan metode bersifat deskriptif. Data diambil dari hasil kuisioner dan sampel feses. Hasil penelitian menunjukkan sebanyak 10 sampel feses negatif. Hasil kuisioner menunjukkan rata-rata siswa memiliki personal hygene dan faktor-faktor kebiasaan yang baik di antaranya, kebiasaan mencuci tangan memakai sabun sebelum dan setelah makan $(86,4 \%)$, kebiasaan mencuci tangan memakai sabun setelah buang air besar $(97,7 \%)$, kebiasaan mencuci tangan memakai sabun setelah bermain tanah $(84,1 \%)$, bermain tanah $(90,9 \%)$, menggunakan alas kaki keluar rumah dan istirahat sekolah $(79,5 \%)$ serta memotong kuku sekali dalam seminggu $(81,8 \%)$. Oleh karena itu, kebiasaan menjaga kebersihan diri diharapkan dapat dipertahankan dalam kehidupan sehari-hari sehingga dapat mengurangi angka infeksi kecacingan anak-anak.
\end{abstract}

Kata kunci : Infeksi kecacingan, sekolah dasar, kebersihan diri

\begin{abstract}
Helmintiasis has been an issue in Indonesia for so long. Soil-transmitted helminths (STHs) remain the main causes of helmintiasi, Children between 5-11 years old are mostly likely to be suscetiple to STHs due to lack personal hygiene. It has been reported that prevalence of hemintiasis was high in elementary schools in West Bandung area. SDN Cimerang, one of the schools in West Bandung, is located in densely residential area, which makes it susceptible to exposure of infection. The present study aimed to observe STHs in feces of students in SDN Cimerang, Cipatat, Bandung Barat. This was descriptive study involving 10 samples from the students. Data were collected from identification of STHs eggs and the follow-up quizionaire regarding personal hygiene of the students. Results showed there was no STHs eggs detected in all samples. Survey of personal hygiene revealed good personal hygene including hand-washing before and after eating (86,4\%), after using the bathroom (97,7\%), after playing outside (84,1\%); playing dirty $(90,9 \%)$, using footwear during outdoor activities (79,5\%), and cutting nails regularly (81,8\%). Thus, personal hygiene should be maintained and improved to reduce the risk of STHs infection in the future.
\end{abstract}

Keywords : Helmintiasis, elementary school, personal hygene

Open Journal System (OJS): journal.thamrin.ac.id

http://journal.thamrin.ac.id/index.php/anakes/issue/view/43 


\section{PENDAHULUAN}

Infeksi telur cacing Nematoda usus merupakan salah satu masalah kesehatan masyarakat di Indonesia, yaitu kecacingan. Manusia merupakan Hospes Nematoda usus sehubungan banyaknya faktor yang menunjang hidup suburnya cacing parasit ini (Amalia, 2017). Penyebab penyakit kecacingan adalah golongan cacing yang ditularkan melalui tanah atau disebut juga Soil Transmitted Helminths (STH). Cara infeksi pada manusia adalah dengan bentuk infektif yang ditemukan dan berkembang di tanah (Akhsin, 2010). Penularan penyakit kecacingan di Indonesia, bersifat endemik. Infeksi kecacingan yang ditularkan melalui tanah atau STH, antara lain cacing gelang (Ascaris lumbricoides), cacing cambuk (Trichuris trichiura), dan cacing tambang (Ancylostoma duodenale dan Necator americanus) (Suharmiati \& Rochmansyah, 2018).

Berdasarkan data dari World Health Organization (WHO), lebih dari 1,5 miliar orang atau 24\% dari populasi dunia terinfeksi STH. Infeksi tersebar luas di daerah tropis dan subtropis, dengan jumlah terbesar terjadi di sub-Sahara Afrika, Amerika, China dan Asia timur. Lebih dari 270 juta anak-anak usia prasekolah dan lebih dari 600 juta anak usia sekolah tinggal di daerah dimana parasit ini secara intensif ditularkan, dan membutuhkan pengobatan dan intervensi pencegahan (WHO, 2014).

Tinggi rendahnya frekuensi infeksi cacing berhubungan erat dengan kebersihan pribadi dan sanitasi lingkungan sebagai sumber infeksi. Infeksi cacing Nematoda usus ditularkan melalui tanah yang tercemar telur cacing. tempat tinggal dan cara hidup yang tidak bersih di pedesaan dan daerah kumuh perkotaan indonesia (Kristinawati \& Jiwantoro, 2020). Sanitasi sekolah, khususnya Sekolah Dasar, sangat memungkinkan menjadi salah satu penyebab infeksi cacing pada anak. Kenyataan yang kita temui pada hampir sebagian besar Sekolah Dasar di pedesaan adalah kondisi sanitasi kamar mandi yang cukup memprihatinkan. Hampir dapat dipastikan perawatan kamar mandi ini kurang baik sehingga area tanah di sekitarnya memiliki sanitasi yang kurang baik. Anak usia sekolah dasar merupakan anak yang memiliki frekuensi bermain relatif tinggi, baik di sekolah maupun di rumah. Perilaku bermain ini tentu tidak dapat dilepaskan dari terjadinya kontak dengan tanah halaman sekolah (Sari \& Hayati, 2020). 
Berdasarkan hasil penelitian sebelumnya (Pasaribu, 2003) pada murid Kelas I SDN Kartika XI Desa Karyawangi Kecamatan Parongpong menunjukkan bahwa prevalensi infeksi cacing tambang sebesar 24,6\% pada anak laki-laki prevalensinya $22,8 \%$ dan pada anak perempuan adalah 26,9\%. Selain itu, prevalensi kecacingan pada murid SDN di Desa Cihanjuang Rahayu adalah 15,5\%. Dari 22 sampel positif, ditemukan 12 sampel (54,5\%) mengandung cacing A. lumbricoides, 7 sampel (31,8\%) mengandung cacing T. trichiura, 1 sampel (4,5\%) mengandung E. vermicularis, dan 2 sampel (9,1\%) mengandung cacing tambang (Silitonga, 2008). Serta pada penelitian yang telah dilakukan sebelumya (Andaruni, 2010) Penyakit Kecacingan di SDN 01 Pasirlangu terdapat 53 positif kecacingan dari 114 siswa. Berdasarkan latar belakang tersebut, peneliti tertarik mengetahui infeksi kecacingan di salah satu Sekolah Dasar yang terletak di daerah Bandung Barat. yaitu SDN Cimerang.

\section{METODE PELAKSANAAN}

Penelitian ini bersifat deskriptif yaitu untuk mengetahui gambaran infeksi telur cacing Nematoda usus pada siswa SDN Cimerang Kecamatan Cipatat Kabupaten Bandung Barat. Sampel dari penelitian ini adalah siswa kelas 1 dan 2 sebanyak 44 orang siswa di SDN Cimerang, Kecamatan Cipatat, Kabupaten Bandung Barat. Jenis data yang dikumpulkan berupa data primer, yaitu hasil kuisioner dan pemeriksaan telur cacing Nematoda usus pada siswa SDN Cimerang dengan metode Flotasi.

Lembar persetujuan (informed consent) diberikan sebelum penelitian dilaksanakan. Pengambilan sampel tinja pada setiap responden digunakan wadah pot plastik $30 \mathrm{ml}$ bersih dengan tutup berulir. Sebelum pot spesimen dibagikan terlebih dahulu diberikan penjelasan kepada siswa cara pengambilan tinja. Tinja diupayakan jangan sampai tercampur dengan urin karena dapat merusak telur cacing. Sebanyak kurang lebih 5 gram sampel tinja dimasukkan ke dalam pot plastik, kemudian dikumpulkan dalam box dan secepatnya dibawa ke laboratorium untuk dilakukan pemeriksaan (Martila dkk., 2015)

Pemeriksaan telur cacing dilakukan dengan menggunakan metode flotasi (pengapungan) (Natadisastra \& Agoes, 2009). Tabung reaksi diisi dengan larutan $\mathrm{NaCl}$ jenuh hingga penuh. Tinja sebanyak 5 gram diletakkan ke dalam gelas kimia berisi $\mathrm{NaCl}$ jenuh dan dihancurkan dengan lidi, sambil ditambah sedikit demi sedikit sampai homogen. Selanjutnya, 
semua larutan $\mathrm{NaCl}$ jenuh dituangkan ke dalam gelas kimia. Tuangkan isi gelas kimia ke dalam tabung reaksi kembali sampai penuh. Bagian kasar pada permukaan dibuang. Kaca penutup diletakkan di atas tabung sehingga menyentuh permukaan larutan, dan didiamkan selama 20-30 menit. Dengan hati-hati kaca penutup diambil, diletakkan di atas kaca objek, kemudian diperiksa di bawah mikroskop cahaya [Olympus CX21] pada perbesaran 40x.

\section{HASIL DAN PEMBAHASAN}

Pada penelitian ini, pemeriksaan dilakukan untuk mengidentifikasi jenis telur cacing pada stadium diagnostik, dimana pada stadium ini telur cacing belum mengalami pematangan. Stadium ini dapat ditemukan dalam sampel feses segar. Sedangkan pada stadium infektif telur sudah mengalami pematangan akibat pengaruh faktor dari lingkungan luar. Pada stadium ini jika manusia kontak langsung dengan tanah yang mengandung telur cacing yang infektif maka dapat terinfeksi. Stadium infektif ini dapat digunakan untuk mengetahui epidemiologi dari cacing dengan menggunakan sampel tanah dan air. Hasil pemeriksaan feses pada siswa SDN Cimerang Kecamatan Cipatat Kabupaten Bandung Barat dapat dilihat pada Tabel 1. Hasil menunjukkan dari 10 orang siswa yang diperiksa fesesnya tidak ditemukan telur cacing golongan Nematoda usus.

Tabel 1. Hasil Identifikasi Sampel Feses Siswa SDN Cimerang

\begin{tabular}{cccc}
\hline No & Kode Sampel & Hasil & Keterangan \\
\hline 1 & SFO1 & $(-)$ & Negatif \\
2 & SF02 & $(-)$ & Negatif \\
3 & SF03 & $(-)$ & Negatif \\
4 & SF04 & $(-)$ & Negatif \\
5 & SF05 & $(-)$ & Negatif \\
6 & SF06 & $(-)$ & Negatif \\
7 & SF07 & $(-)$ & Negatif \\
8 & SF08 & $(-)$ & Negatif \\
9 & SF09 & $(-)$ & Negatif \\
10 & SF10 & $(-)$ & Negatif \\
\hline
\end{tabular}

Keterangan : $\mathrm{SF}=$ Sampel Feses 
Hasil negatif yang diperoleh dalam pemeriksaan telur cacing Nematoda usus juga ditunjang dari hasil wawancara melalui kuisioner (Gambar 1). Hampir seluruh responden umumnya memiliki tingkat personal hygiene yang baik, terlihat dari setiap pertanyaan yang diajukkan kepada responden mencapai hasil pesentase yang tinggi, yaitu 86,4\% responden yang mencuci tangan memakai sabun sebelum dan setelah makan, 97,7\% responden yang mencuci tangan memakai sabun setelah buang air besar, $84,1 \%$ responden yang mencuci tangan memakai sabun setelah bermain tanah, 90,9\% responden yang bermain tanah, 79,5\% responden yang menggunakan alas kaki keluar rumah dan istirahat sekolah serta 81,8\% responden yang memotong kuku sekali dalam seminggu sehingga dapat mengurangi resiko responden terinfeksi kecacingan.

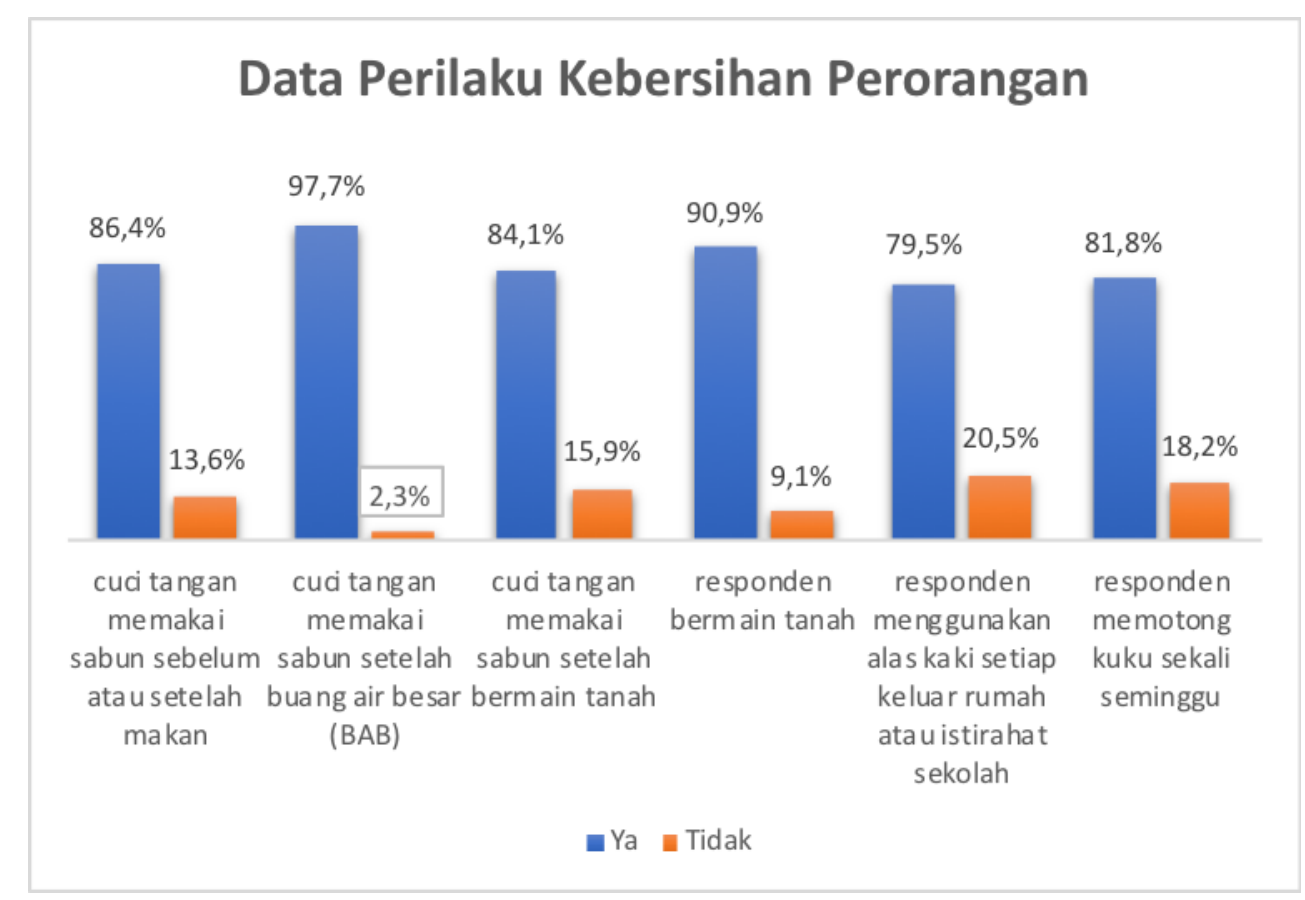

Gambar 1: Hasil Kuisioner Mengenai Perilaku Kebersihan Perorangaan

Berdasarkan rentang usia anak 6-15 tahun adalah penderita infeksi kecacingan terbanyak. Penyebab infeksi kecacingan adalah kebiasaan anak-anak yang tidak mencuci tangan sebelum makan, bermain dengan tidak menggunakan alas kaki, jajan di sembarang tempat, kuku panjang dan kotor. Infeksi kecacingan dapat memperlambat pertumbuhan anak, 
serta dapat berakibat buruk pada kemampuan anak mengikuti pelajaran di sekolahnya (WHO, 2003).

Pemeliharaan kebersihan diri sangat menentukan status kesehatan, hal tersebut akan membuat individu secara sadar atas inisiatif pribadi mampu menjaga kesehatan dan mencegah terjadinya penyakit (Ali dkk., 2016). Cara menjaga kebersihan diri dapat dilakukan dengan mencuci tangan sebelum dan sesudah makan, kuku digunting pendek dan dibersihkan agar tidak melukai kulit kaki. Sanitasi lingkungan juga perlu dijaga sebagai upaya pengendalian faktor-faktor lingkungan fisik manusia yang dapat berpengaruh buruk terhadap kesehatan, misalnya menyediakan air bersih, pembuangan tinja, penanganan makanan, dan keselamatan lingkungan kerja agar terhindar dari infeksi kecacingan (Ali dkk., 2016). Menurut WHO (2003), tindakan rutin mencuci tangan adalah tindakan paling utama dan menjadi salah satu cara mencegah terjadinya penularan penyakit, dan tujuan utamanya secara higienik adalah untuk menghalangi transmisi kuman patogen secara cepat dan efektif.

Keterbatasan penelitian juga menjadi salah satu faktor penyebab penelitian menghasilkan hasil yang negatif. Seperti keterbatasan sampel, keterbatasan responden dalam mengisi kuisioner dan populasi yang kurang luas. Selain hal tersebut waktu pengambilan sampel juga harus dipertimbangkan karena dikhawatirkan parasit-parasit yang berada dalam sampel mengalami perubahan dalam bentuk maupun siklus hidupnya. Adapun keterbatasan penelitian dengan menggunakan kuisioner yaitu terkadang jawaban yang diberikan oleh sampel tidak menunjukkan keadaan yang sesungguhnya.

\section{SIMPULAN}

Pada penelitian ini, tidak ditemukan telur cacing Nematoda usus pada feses siswa SDN Cimerang Kecamatan Cipatat Kabupaten Bandung Barat. Penelitian terkait gambaran telur cacing Nematoda usus diharapkan terus dilakukan kedepannya di beberapa sekolah lainnya.

\section{REFERENSI}

Akhsin, Z. (2010). Parasitologi. Yogyakarta: Nuha Medika. 
Ali, R.U., Zulkarnaini, Z. and Affandi, D. (2016). Hubungan personal hygiene dan sanitasi lingkungan dengan angka kejadian kecacingan (soil transmitted helminth) pada petani sayur di kelurahan maharatu kecamatan marpoyan damai kota pekanbaru. Dinamika Lingkungan Indonesia, 3(1), pp.24-32.

Amalia, Astri Nur. (2017). Study of Soil-Transmitted Helminthiasis Prevalence in School Childreen in Surabaya. Journal of Vocational Health Study. 1(1): 23-26.

Andaruni, A. (2010). Gambaran Faktor-Faktor Penyebab Infeksi Cacingan Pada Anak di SDN 01 Pasirlangu Cisarua.

Kristinawati, E. dan Jiwantoro, Y. (2020). Prevalensi Nematoda Usus Golongan Sth (Soil Transmitted Helminth) Pada Masyarakat Yang Menggunakan Kotoran Sapi Di Dusun Sade Sebagai Bahan Pembersih Lantai. Jurnal Analis Medika Biosains (JAMBS), 7(1), pp.68-74.

Martila, Sandi, S., Paembonan, \& Nopita. (2015). Hubungan Higiene Perorangan dengan Kejadian Kecacingan pada murid SD negeri Abe pantai Jayapura.

Pasaribu, M. R. (2003). Pemeriksaan infeksi cacing tambang dengan teknik natif pada murid kelas I SDN Kartika XI- 12 Desa Karyawangi Parongpong Bandung (Skripsi). Bandung, Universitas Advent Indonesia

Sari, N.P. dan Hayati, Z. (2020). Kebersihan Perorangan dan Kecacingan pada Siswa SDN 128 Pekanbaru. Jurnal Ilmiah Kesehatan Masyarakat: Media Komunikasi Komunitas Kesehatan Masyarakat, 12(4), pp.176-182.

Silitonga, M. M. (2008). Prevalensi Kecacingan Pada Murid Sekolah Dasar Negeri di Desa Cihanjuang Rahayu Parompong Bandung Barat.

Soedarto. (2011). Buku Ajar Parasitologi Kedokteran. Jakarta: Sagung Seto.

Suharmiati, S. dan Rochmansyah, R. (2018). Mengungkap Kejadian Infeksi Kecacingan Pada Anak Sekolah Dasar (Studi Etnografi Di Desa Taramanu Kabupaten Sumba Barat). Buletin Penelitian Sistem Kesehatan, 21(3), pp.211-217.

WHO. (2014). Infeksi Soil Transmitted Helminths. 